\title{
Alpha-N-acetylglucosaminidase Measurement
}

National Cancer Institute

\section{Source}

National Cancer Institute. Alpha-N-acetylglucosaminidase Measurement. NCI Thesaurus. Code C147299.

The determination of the amount of alpha- $\mathrm{N}$-acetylglucosaminidase present in a sample. 